Letters

Elsevier Editorial system(tm) for Economics

Manuscript Draft

Manuscript Number:

Title: High frequency trading, price discovery and market efficiency in the FTSE100

Article Type: Full length article

Keywords: High frequency trading; price discovery; market efficiency.

Corresponding Author: Dr. Vitor Leone, PhD

Corresponding Author's Institution: DMU-LCBS

First Author: Vitor Leone, PhD

Order of Authors: Vitor Leone, PhD; Frank Kwabi

Abstract: This study examines the role of high frequency trading in price discovery and efficiency in the FTSE100 index tick changes. Using a unique data set, we find that there is no random walk when investors extract information at a millisecond to a second. Further analysis provides evidence that the information cannot be extracted by investors at frequencies starting from 10 minutes. This is consistent with the view that the market already experiences a random walk, which contributes to the weak form of market efficiency.

Suggested Reviewers: Chandra Thapa PhD

Reader in Finance, Accounting and Finance, University of Strathclyde chandra. thapaestrath.ac.uk

Expert in the research area.

Anna Du PhD

Senior Lecturer, Accounting and Finance, Leeds Beckett University

m.du@leedsbeckett.ac.uk

Expert in the research area.

Piers Thompson PhD

Associate Professor, Economics Division, Nottingham Trent University piers.thompsonentu.ac.uk

Research Data Related to this Submission

There are no linked research data sets for this submission. The following reason is given:

The authors do not have permission to share data 
High frequency trading, price discovery and market efficiency in the FTSE100

\section{Highlights}

- Price discovery is exploited at millisecond and second frequencies.

- HFT contributes to the weak form of market efficiency.

- Information cannot be extracted by investors from 10 minutes. 
High frequency trading, price discovery and market efficiency in the FTSE100

\author{
Vitor Leone $^{\mathrm{a}^{*}}$, Frank Kwabi ${ }^{\mathrm{a}}$
}

* Corresponding author

\footnotetext{
${ }^{a *}$ Department of Accounting and Finance, De Montfort University, England, LE1 9BH,Tel: +44 (0) 116250 6463, Email: vitor.leone@dmu.ac.uk

$\mathrm{a}^{*}$ Department of Accounting and Finance, De Montfort University, England, LE1 9BH,Tel: +44 (0) 116201 3862, Email: frank.kwabi@dmu.ac.uk
} 


\title{
High frequency trading, price discovery and market efficiency in the FTSE100
}

\begin{abstract}
This study examines the role of high frequency trading in price discovery and efficiency in the FTSE100 index tick changes. Using a unique data set, we find that there is no random walk when investors extract information at a millisecond to a second. Further analysis provides evidence that the information cannot be extracted by investors at frequencies starting from 10 minutes. This is consistent with the view that the market already experiences a random walk, which contributes to the weak form of market efficiency.
\end{abstract}

JEL classification: $C 1 ;$; 1

Key words: High frequency trading; price discovery; market efficiency 


\section{Introduction}

In the last 30 years fast paced technological advancements and their rapid uptake in equity markets have markedly increased the importance of high frequency trading (HFT). Sahalia and Saglam (2014) show that HFT represents between 40 and $70 \%$ of the trading volume in the US and slightly less in the Canadian, European and Australian markets.

As HFT may prevent all market participants from having equal access to information, there have been ongoing debates regarding its impact on making stock markets inefficient ${ }^{1}$. Theoretical arguments and empirical evidence indicate many supposed benefits of HFT and algorithmic trading (AT), such as decrease in bid ask spread and transaction cost for equity investors (Jones, 2013; O’Hara, 2015), price discovery and efficiency (Hendershott, 2012), quality and liquidity Linton and Mahmoodzadeh (2018). In contrast, evidence also shows that HFT might contribute negatively to the development of stock markets; for instance, the May 6, 2010 flash clash and the October 15, 2014 bond market flash. This suggests that HFT may play a role in price instability and market volatility. It is therefore important to have a better understanding of the role of HFT with regard to price discovery and efficiency

Studies on HFT and its roles in financial market performance have been very limited due to the unavailability of data (Brogaard et al., 2014) ${ }^{2}$, and most of the research is USbased with few studies using the UK at frequencies in the millisecond and second brackets. Our study contributes to the relatively scarce empirical literature on HFT and the ongoing debate with regard to the varying impacts of HFT (Hendershott, 2012). Other studies argue that the impacts of HFT on price discovery and price efficiency are unclear (Foucault et al., 2013; Martinez and Rosu, 2013). In this paper, we use a unique data set which records in real

\footnotetext{
${ }^{1}$ For the precise definition of HFT and AT, please see SEC (2014).

${ }^{2}$ Markets and regulators are the main sources of these and HFT and other traders tend to oppose realising data.
} 
time the changes in the tick of the FTSE100 price index by millisecond ${ }^{3}$. The data are line with the identification meaning of HFT, which is characterised by traders making use of ultra-high speed connections with trading venues and sophisticated algorithms to exploit market inefficiencies. We find that HFT can predict future price changes in the FTSE100 at a millisecond and a second, suggesting the rejection of the random walk hypothesis. Brogaard et al. (2014), also using data gathered in milliseconds for the NASDAQ and the New York Stock Exchange (NYSE), found similar results over horizons of less than 3 to 4 seconds.

Our findings suggest that HFT at a millisecond and a second contributes to price discovery and market efficiency. The result is robust to the role of high frequency traders, who, by having better information, will perhaps promote price efficiency by trading in the opposite direction to transitory pricing errors and in the same direction as future price changes. Besides, our analysis at 10 minutes to 15 minutes indicates that prices traded within these frequencies' intervals cannot be forecasted by using historical information as the market is already efficient at least in a weak form.

This study has a policy implication with regard to the re-examining of rules requiring trading in markets with HFT if it influences price efficiency. Studies have shown that HFT is associated with two sources of public information: macroeconomic news announcements (Andersen et al., 2003) and imbalances in limited order Books (Cao, Hansch and Wang, $2009)^{4}$. Nevertheless, with regulators worldwide focusing their attention on the impact of HFT, the main concern is to make sure that markets do not become race tracks preventing normal slow investors to trade due to unfair disadvantage.

\footnotetext{
${ }^{3}$ To the best of our knowledge, research focused on the UK market using millisecond data is very scarce.

${ }^{4}$ Sahalia and Saglam (2014) provide a summary of worldwide rules and regulations imposing transaction tax and minimum time limits on HFT.
} 


\section{Data and estimation strategy}

Data showing changes in the FTSE100 tick at the millisecond and second frequencies were obtained from the Centre for Digital Finance at the University of Southampton ${ }^{5}$. We sourced data covering 1, 5, 10, and 15 minutes frequencies from Bloomberg. The study covers tick changes during normal opening and closing market times from 01/04/2011 to 31/05/2012. The millisecond data has over 27 million data points, or 92,000 daily average changes in the FTSE100 tick.

\section{[Insert Table 1 about here]}

For all frequencies the price series exhibits negative skewness, implying that negative price changes are to be more likely than positive ones. Fat tailed distributions (Kurtoses) are identified for $(1,5,15$, minutes). The Jarque-Bera normality test shows strong evidence against normality.

Weak form market efficiency states that prices traded in a securities market cannot be forecasted by using historical price information. This implies that prices traded in such a market are serially uncorrelated. The usual method that has been adopted in the extant literature for testing weak form market efficiency has been an examination of asset prices for evidence of non-random behaviour. The random walk hypothesis (RWH) posits that successive price changes in an efficient market are random. In other words, if the RWH is rejected prices are predictable, suggesting market inefficiency and price discovery ${ }^{6}$. In this study, we apply Low and MacKinlay (1988) variance ratio test ${ }^{7}$ and Chow and Denning (1993) multiple comparison variance ratio test. The individual variance ratio test proposed by

\footnotetext{
5 The acquisition of the data was sponsored by seedcorn funding money provided by Nottingham Trent University.

${ }^{6}$ Most of the past studies of the behaviour of the UK stock market prices have accepted weak form market efficiency (Cunningham, 1973).

${ }^{7}$ Braunies and Mestel (2018).
} 
Lo and MacKinlay tests the proportionality (linearity) of the variance of $k$-differences of the index series, with the first difference. It assumes that, for a random walk series, the variance of its $k$-differences is $k$ times the variance of its first difference. For example, if a series follows a random walk, the variance of its ten-millisecond differences will be 10 times larger than the variance of its one-millisecond differences. Chow and Denning's test is a joint null hypothesis test for all periods considered. Both tests are performed in their heteroskedastic robust version. We have chosen 2, 5, 10 and $30 k$-differences following Belaire-Franch and Opong (2005).

\section{Results}

The empirical results using the individual and joint tests, are reported in Table 2 and Figures 1 to 4 . It is important to highlight that variances' ratios approximately equal to one indicate that markets are efficient in their weak form. However, ratios greater than one suggest a momentum process or a positive serial correlation, whilst values less than one indicate a mean-reversion process or negative autocorrelation.

\section{[Insert Table 2 about here]}

Table 2 shows that at a millisecond, the FTSE100 tick changes do not follow a random walk and information could be extracted by investors, signalling market inefficiency and possible arbitrage exploitation. The variance ratio exceeds 1 and subsequently increases to 2.89 at a 30 millisecond difference. The speed and number of orders in a millisecond time frame market may be responsible for a highly volatile market, which is consistent with a standard deviation of 300.30. Moving to a second change, the test results also suggest a rejection of the RWH and the increase in the variance ratios is even more prominent than at a 
millisecond. The ratio increases from 1.48 at 2 seconds difference to 4.37 at 30 seconds difference. Those results are in line with Brogaard et al. (2014).

As the frequency of the FTSE100 tick changes decreases, price discovery starts to become blurred, for example at both 1 and 5 minutes' time horizons the 30 period differences become statistically insignificant. Another interesting result is the movement from a momentum pattern at 1 minute to mean-reversion at 5 minutes, suggesting trading against possible transient pricing errors. At 10 and 15 minutes the RWH is accepted, suggesting at this time horizon ${ }^{8}$ that markets are likely to be efficient or any price discrepancy would have been already exploited. Overall the Chow and Denning joint test confirms the RWH at 10 and 15 minute intervals.

Critics of HFT might argue that investors who do not have access to this type of information (in general free information is provided with a 15 minute delay) will face competitive disadvantage if they do not have a long-term horizon strategy. These findings are consistent with recent studies which argue that HFT provides a utile service to markets by making prices more efficient (Foucault et al., 2013; Martinez and Rosu, 2013).

\section{Conclusion}

In this paper, we show that HFT contributes to price discovery and stock market efficiency using a unique data set. We provide evidence that there is no random walk when investors extract information at a millisecond to a second. This suggests investors can use the extracted information to earn higher returns. However, we find that the stock market experiences a random walk when information is extracted beginning from 10 minutes.

This study has implications for arbitrage trading.

\footnotetext{
${ }^{8}$ Similar results are replicated for the $30,60,120,240$ minutes, daily and available on request.
} 
Table 1: Descriptive Statistics FTSE100 Price Tick Changes by Frequency

\begin{tabular}{|l|r|r|r|r|r|r|}
\hline FTSE100 & Millisecond & Second & 1 Min & 5 Min & 10 Min & 15 Min \\
\hline Mean & 5650.236 & 5695.378 & 5792.456 & 5794.681 & 5642.375 & 5792.753 \\
\hline Median & 5717.42 & 5770.78 & 5824.33 & 5844.39 & 5706.425 & 5849.83 \\
\hline Maximum & 6105.77 & 6105.755 & 6103.18 & 6098.35 & 6098.14 & 6097.19 \\
\hline Minimum & 4791.01 & 4791.667 & 5256.22 & 5257.83 & 4842.92 & 5257.83 \\
\hline Std. Dev. & 300.3083 & 286.2801 & 181.5778 & 185.4805 & 282.5729 & 192.2746 \\
\hline Skewness & -0.507585 & -0.68439 & -0.96409 & -0.98459 & -0.4766 & -0.93972 \\
\hline Kurtosis & 2.119129 & 2.388053 & 3.659842 & 3.578652 & 2.137324 & 3.338011 \\
\hline Jarque-Bera & 2049982 & 770181.8 & 14626.83 & 2843.614 & 1045.799 & 765.9291 \\
\hline Probability & 0 & 0 & 0 & 0 & 0 & 0 \\
\hline Sum & $1.54 \mathrm{E}+11$ & $4.68 \mathrm{E}+10$ & $4.90 \mathrm{E}+08$ & 93879633 & 85685110 & 29201265 \\
\hline Sum Sq. Dev. & $2.46 \mathrm{E}+12$ & $6.74 \mathrm{E}+11$ & $2.79 \mathrm{E}+09$ & $5.57 \mathrm{E}+08$ & $1.21 \mathrm{E}+09$ & $1.86 \mathrm{E}+08$ \\
\hline Observations & 27234699 & 8222382 & 84523 & 16201 & 15186 & 5041 \\
\hline
\end{tabular}


Table 2: Variance Ratio Test Results

\begin{tabular}{|c|c|c|c|c|c|c|c|c|c|c|c|c|}
\hline \multicolumn{4}{|c|}{ Millisecond } & & \multicolumn{3}{|c|}{ Second } & & \multicolumn{4}{|c|}{1 Minute } \\
\hline \multirow[t]{2}{*}{ Joint Tests } & & Value & df & Probability & & \multirow{2}{*}{$\begin{array}{c}\text { Value } d \\
126.671\end{array}$} & & \multirow{2}{*}{$\begin{array}{r}\text { Probability } \\
0\end{array}$} & \multirow{2}{*}{\multicolumn{2}{|c|}{$\begin{array}{l}\text { Value } d \\
5.278174\end{array}$}} & df & Probability \\
\hline & & 182.6771 & 27234698 & 0 & & & 8222381 & & & & 84522 & \\
\hline \multicolumn{13}{|c|}{ Individual Tests } \\
\hline \multirow[t]{5}{*}{ Period } & Var. Ratio & Std. Error & z-Statistic & Probability & Var. Ratio & Std. Error & z-Statistic & Probability & Var. Ratio & Std. Error & z-Statistic & Probability \\
\hline & 1.077712941 & \begin{tabular}{l|l}
1 & 0.001968
\end{tabular} & 39.4840263 & 0 & 1.479555 & 0.010957 & 43.76815 & 0 & 1.037752 & 0.007152 & 5.278174 & \\
\hline & 1.323457078 & $\begin{array}{ll}3 & 0.00418\end{array}$ & 77.3795533 & 0 & 2.22417 & 0.018411 & 66.49116 & 0 & 1.054154 & $\begin{array}{ll}7 & 0.013264\end{array}$ & 4.082746 & \\
\hline & 1.705412162 & 0.006068 & 116.253379 & 0 & 2.971067 & 0.021871 & 90.12115 & 0 & 1.048808 & $\begin{array}{ll}3 & 0.018639\end{array}$ & 2.618613 & 0.0088 \\
\hline & 2.839267025 & 0.010068 & 182.6771 & 0 & 4.369523 & 0.026601 & 126.671 & 0 & 1.034317 & 7) 0.027191 & 1.262061 & 0.2069 \\
\hline \multicolumn{4}{|c|}{5 Minutes } & & \multicolumn{4}{|c|}{\begin{tabular}{|c|}
10 Minutes \\
\end{tabular}} & \multicolumn{4}{|c|}{15 Minutes } \\
\hline \multirow[t]{2}{*}{ Joint Tests } & & Value & df & Probability & & Value & & Probability & & Value & df & Probability \\
\hline & & 2.281556 & 16200 & 0.0871 & & 1.324156 & 15185 & 0.5598 & & 1.215067 & 5040 & 0.638 \\
\hline \multicolumn{13}{|c|}{ Individual Tests } \\
\hline Period & Var. Ratio & Std. Error & z-Statistic & Probability & Var. Ratio & Std. Error & z-Statistic & Probability & Var. Ratio & Std. Error & z-Statistic & Probability \\
\hline 2 & 0.977024 & + 0.01007 & -2.281556 & 0.0225 & 0.983285 & 0.012623 & -1.324156 & 0.1855 & 0.999343 & 30.010419 & -0.063046 & 0.9497 \\
\hline 5 & 0.952501 & 0.02099 & -2.262956 & 0.0236 & 0.972641 & 0.028106 & -0.9734 & 0.3304 & t 1.01158 & $\begin{array}{ll}30.026662\end{array}$ & 0.434326 & 0.6641 \\
\hline 10 & 0.948545 & 0.030912 & -1.66457 & 0.096 & 0.984594 & 0.042122 & -0.365751 & 0.7146 & 1.049323 & 0.040593 & 1.215067 & 0.2243 \\
\hline 30 & 0.991345 & 0.052158 & -0.165931 & 0.8682 & 1.063892 & 0.071924 & 0.88832 & 0.3744 & +1.025668 & $\begin{array}{ll}3 \quad 0.073869\end{array}$ & 0.347483 & 0.7282 \\
\hline
\end{tabular}




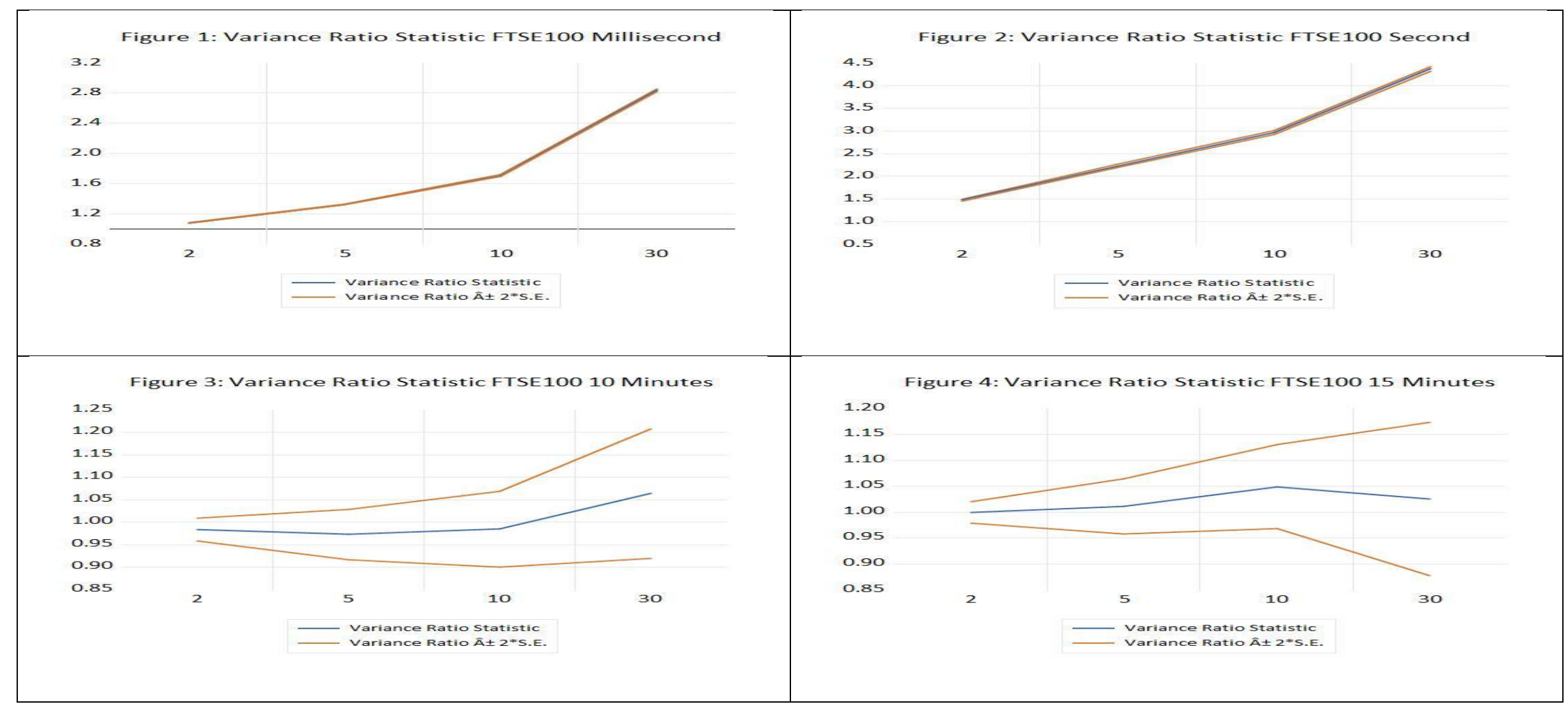




\section{References}

Andersen, T., Bollerslev, T. Diebold, F., Vega, C., 2003. Micro Effects of Macro Announcements: Real-Time Price Discovery in Foreign Exchange. American Economic Review 93, 38-62.

Belaire-Franch, J., Opong, K., 2005. A variance ratio test of the behaviour of some FTSE equity indices using ranks and signs, Review of Quantitative Finance and Accounting, 24, 9-107.

Braunies A., Mestel R., 2018. Price Discovery of cryptocurrencies: Bitcoin and Beyond. Economics Letters, 165, 59-61.

Brogaard, J., Hendershott, T., Riordan, R., 2014. High-frequency trading and price discovery. Review of Financial Studies, 27, 2267-2306.

Cao, C., Hansch, O., Wang, X., 2009. The Information Content of an Open Limit-Order Book. Journal of Futures Markets 29, 16-41.

Chow K.V., Denning K.C., 1993. A simple multiple variance ratio test, Journal of Econometrics, 58, 385-401.

Cunningham, S. W., 1973. The Predictability of British Stock Market Prices, Applied Statistics 22, 215-23.

Foucault, T., Kadan, O., Kandel, E., 2013. Liquidity cycles and make/take fees in electronic markets. Journal of Finance 68, 299-341.

Hendershott, T., 2012. High frequency trading and price efficiency. Government office for science, Foresight project. DR12.

Jones, C. M., 2013. What do we know about high frequency trading? Columbia Business School research Paper No. 13-11.

Linton, O., Mahmoodzadeh, S., 2018. Implications of high frequency trading for security markets. Annual Review of Economics 10, 237-259.

Lo, A.W., MacKinlay A.C., 1988. Stock market prices do not follow random walk: Evidence from a simple specification test, The Review of Financial Studies, 1, 41-66.

Martinez, C., Rosu, I., 2013. High frequency traders, news and volatility. Working paper.

O’Hara, M., 2015. High frequency market microstructure. Journal of Financial Economics $116,257-270$.

Sahalia, Y.A., Saglam, M., 2014. High Frequency traders taking advantage of speed, NBER working paper-19531, http://ssrn.com/abstract=2331613 
Security Exchange Commission, 2014. Equity Market Structure Literature Review Part II: High Frequency Trading, Staff of the Division of Trading and Markets, https://www.sec.gov/marketstructure/research/hft_lit_review_march_2014.pdf 